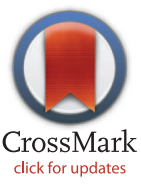

\section{G openaccess}

Citation: Vojnov L, Markby J, Boeke C, Harris L, Ford N, Peter T (2016) POC CD4 Testing Improves Linkage to HIV Care and Timeliness of ART Initiation in a Public Health Approach: A Systematic Review and Meta-Analysis. PLoS ONE 11(5): e0155256. doi:10.1371/journal.pone. 0155256

Editor: Pierre Roques, CEA, FRANCE

Received: January 7, 2016

Accepted: April 26, 2016

Published: May 13, 2016

Copyright: @ 2016 Vojnov et al. This is an open access article distributed under the terms of the Creative Commons Attribution License, which permits unrestricted use, distribution, and reproduction in any medium, provided the original author and source are credited.

Data Availability Statement: All relevant data are within the paper and its Supporting Information files.

Funding: This work was funded by a UNITAID grant (LV CB LH TP): Accelerating access to innovative point of care HIV technologies; and by DFID (LV CB LH TP): Market-Shaping for Access to Safe, Effective and Affordable Health Commodities. The funders had no role in study design, data collection and analysis, decision to publish, or preparation of the manuscript.

Competing Interests: The authors have declared that no competing interests exist.
RESEARCH ARTICLE

\section{POC CD4 Testing Improves Linkage to HIV Care and Timeliness of ART Initiation in a Public Health Approach: A Systematic Review and Meta-Analysis}

\author{
Lara Vojnov $^{1 *}$, Jessica Markby ${ }^{2}$, Caroline Boeke ${ }^{1}$, Lindsay Harris ${ }^{1}$, Nathan Ford ${ }^{2}$, \\ Trevor Peter ${ }^{1}$ \\ 1 Clinton Health Access Initiative, Boston, MA, United States of America, 2 World Health Organization, \\ Geneva, Switzerland \\ *Ivojnov@clintonhealthaccess.org
}

\section{Abstract}

\section{Background}

CD4 cell count is an important test in HIV programs for baseline risk assessment, monitoring of ART where viral load is not available, and, in many settings, antiretroviral therapy (ART) initiation decisions. However, access to CD4 testing is limited, in part due to the centralized conventional laboratory network. Point of care (POC) CD4 testing has the potential to address some of the challenges of centralized CD4 testing and delays in delivery of timely testing and ART initiation. We conducted a systematic review and meta-analysis to identify the extent to which POC improves linkages to HIV care and timeliness of ART initiation.

\section{Methods}

We searched two databases and four conference sites between January 2005 and April 2015 for studies reporting test turnaround times, proportion of results returned, and retention associated with the use of point-of-care CD4. Random effects models were used to estimate pooled risk ratios, pooled proportions, and $95 \%$ confidence intervals.

\section{Results}

We identified 30 eligible studies, most of which were completed in Africa. Test turnaround times were reduced with the use of POC CD4. The time from HIV diagnosis to CD4 test was reduced from 10.5 days with conventional laboratory-based testing to 0.1 days with POC CD4 testing. Retention along several steps of the treatment initiation cascade was significantly higher with POC CD4 testing, notably from HIV testing to CD4 testing, receipt of results, and pre-CD4 test retention (all $p<0.001$ ). Furthermore, retention between CD4 testing and ART initiation increased with POC CD4 testing compared to conventional laboratory-based testing $(p=0.01)$. We also carried out a non-systematic review of the literature 
observing that POC CD4 increased the projected life expectancy, was cost-effective, and acceptable.

\section{Conclusions}

POC CD4 technologies reduce the time and increase patient retention along the testing and treatment cascade compared to conventional laboratory-based testing. POC CD4 is, therefore, a useful tool to perform CD4 testing and expedite result delivery.

\section{Introduction}

Many HIV patients currently do not have reliable access to essential diagnostic laboratory tests, including CD4, clinical chemistry, hematology, viral load, and diagnosis of common coinfections. CD4 testing is critical for identifying patients most in need of clinical care and antiretroviral therapy (ART) [1-4]. While there is a progressive move away from CD4 cell count as the main way to determine eligibility for ART [5], CD4 cell count testing still has an important role to play in baseline risk assessment, prioritizing patients when limited ART drug supplies exist, and diagnosing treatment failure in settings where access to viral load monitoring is limited [6,7]. Furthermore, CD4 testing remains beneficial for HIV disease and opportunistic infection management of patients on ART.

Conventional laboratory-based CD4 testing presents several key challenges including use of complicated equipment that is poorly adapted for resource-limited settings, requires un-interrupted power supply, cold chain logistics for reagents, regular technical support and maintenance, and a high skill level for operation as well as large capital outlay for equipment. Due to these constraints, conventional CD4 testing is limited to higher tiered laboratory settings that often limit the access to testing. Transport of whole blood samples to centralized laboratories and return of results to clinical sites is a challenge in resource-limited settings often resulting in invalid specimens, inaccurate results, long turn around times for results or lost results. Delays caused by conventional testing and result delivery can lead to patients being lost before ART initiation [8].

Several studies have highlighted the need to improve patient retention prior to ART initiation in the current cascade of care [8-11]. Just over half of known HIV-positive patients receive a CD4 test result, while less than three-quarters of patients determined eligible are initiated on ART [9-11]. Pre-ART retention has been substantially low at under $50 \%$ in previous metaanalyses $[9,11]$. The requirement of multiple visits for sample collection, results received, and clinical decision-making can lead to increased transportation costs and distances, long waiting times, and the requirement to take time away from work, all of which are associated with loss [8].

POC diagnostic technologies may alleviate some of these burdens on the health care system by decentralizing care and testing, providing immediate test results, and allowing for expedited clinical decisions. Several POC CD4 technologies are currently on the market [12] and several are in the development pipeline. POC CD4 technologies can reduce the number of trips to the health care facility required of patients in the pre-ART staging process, thus decreasing costs, effort and time away from work. Same day HIV diagnosis, CD4 testing, and ART eligibility assessments can lower the pre-ART attrition observed in most high HIV burden settings [13].

A previous systematic review published in 2013 reported improved retention along the testing and treatment cascade with the introduction and use of POC CD4 technologies [14]; however, this review was conducted early in the adoption of POC CD4 and the number of studies contributing 
to the review was small and limited in the number of outcomes it was able to assess. We conducted this systematic review and meta-analysis to update the patient impact of POC CD4 compared to conventional laboratory-based testing to support the 2016 revision of the World Health Organization (WHO) guidelines for the treatment and care of people living with HIV.

\section{Methods}

\section{Search strategy and study selection}

Standard global guidelines were followed for the search strategy and study selection including the Preferred Reporting Items for Systematic Reviews and Meta-Analyses (PRISMA) [15] (S1 Fig). PubMed and EMBASE databases were searched from 1 January 2005 to 15 April 2015. Search terms were developed using the PICO question format (population, intervention, comparator, outcome). The search terms were, therefore, broken into four categories: HIV (population), POC (intervention), CD4 (intervention/comparator), and outcomes. Characteristics of POC technologies as well as manufacturer names were included to maximize study identification as well as an extensive list of outcomes (S2 Fig). Conference abstracts within the search dates from the Conference on Retroviruses and Opportunistic Infections (CROI), International Conference on AIDS and STIs in Africa (ICASA), International AIDS Society (IAS), and AIDS Conference and bibliographies were also screened and reviewed for possible inclusion. Search terms included characteristics of POC technologies, outcome terms, and manufacturer names to maximize study identification. Two independent reviewers screened all titles and abstracts for eligibility. Studies were included if they compared the impact of POC to laboratory-based $\mathrm{CD} 4$ testing in HIV-positive patients. No geographical region or age restrictions were applied. Only English language studies were considered for inclusion. Data was extracted from each study included: the POC CD4 technology used, sample size, test setting, study dates, and key outcomes as defined in the study protocol. Studies were assessed for quality, bias and applicability using the QUADAS-2 guidelines [16].

\section{Data analysis}

The primary outcomes of interest were time and retention along the testing and treatment cascade. Secondary outcomes included cost-effectiveness and acceptability. To determine the presence of between-study heterogeneity, the Q-statistic was calculated [17]. Random effects models were used to estimate the pooled summary measures for turnaround time, proportions of retention, risk ratios, and 95\% confidence intervals. For the random effects model of proportions, the metaprop command was used in Stata with a continuity correction value of 0.5 and exact confidence intervals. To calculate risk ratios, the metan command was used, specifying use of the DerSimonian and Laird method using the inverse-variance fixed effect model for the estimate of heterogeneity. Weighted averages were used to compare continuous outcomes for patients tested with a POC technology compared to those tested with a conventional laboratory-based technology.

Two researchers independently performed the statistical analysis to ensure accuracy. Graphic representations were completed in GraphPad Prism v6.0 (La Jolla, California, USA) and analyses were completed in Stata 13 (College Station, Texas, USA).

\section{Results}

\section{Study characteristics and assessment}

The search strategy yielded 30 studies relevant to the study question (Fig 1 and Table 1) $[13,18-46]$. Almost 40,000 total patients were included in the analysis, while the median 


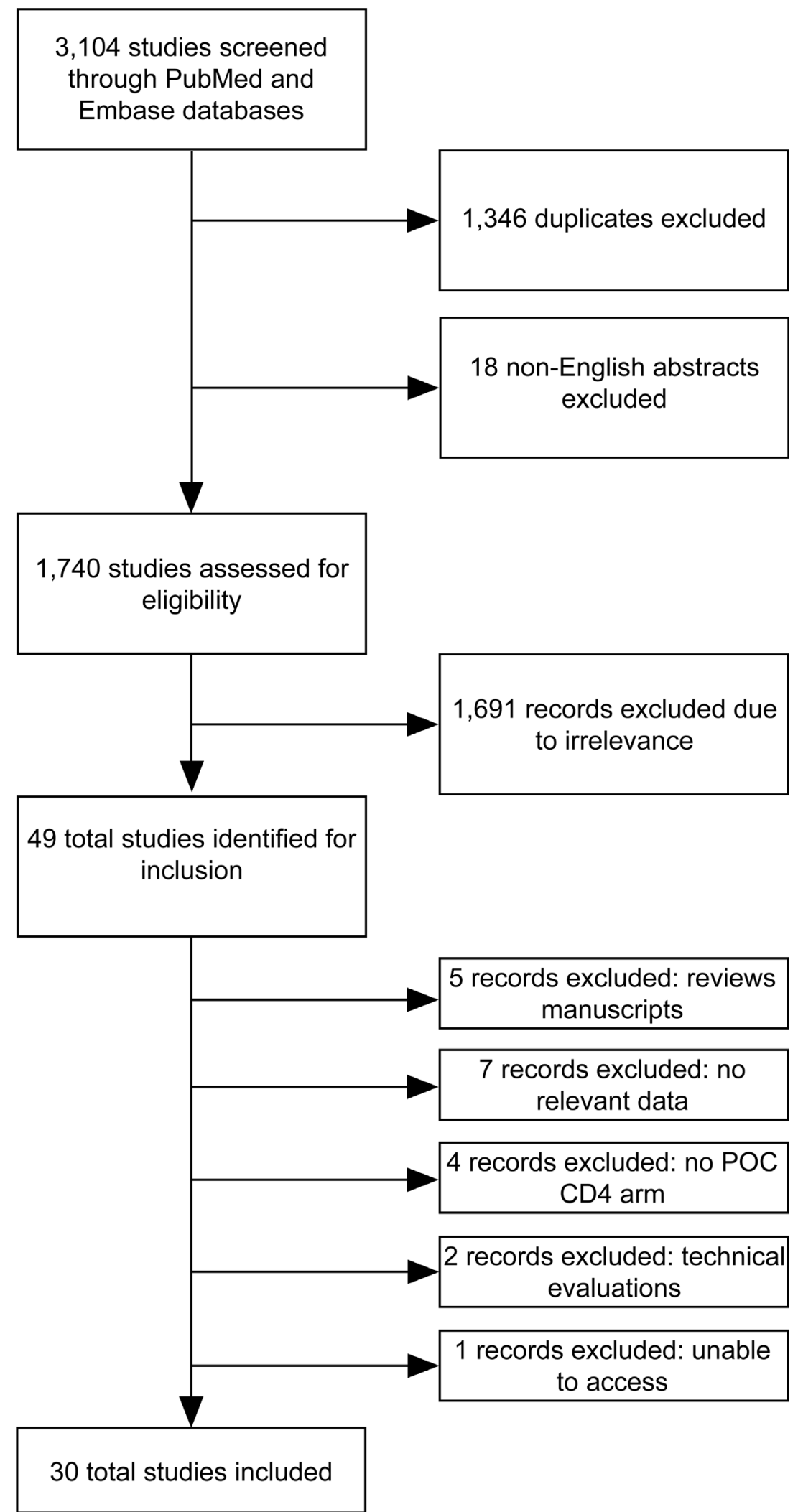

Fig 1. PRISMA diagram of search outcome and included studies.

doi:10.1371/journal.pone.0155256.g001 
Table 1. Study characteristics.

\begin{tabular}{|c|c|c|c|c|c|c|c|c|c|c|}
\hline$\#$ & Author & Journal & Year & $\begin{array}{l}\text { Countries of } \\
\text { study }\end{array}$ & Type of study & $\begin{array}{l}\text { Years } \\
\text { of } \\
\text { study }\end{array}$ & Site type & Population & $\begin{array}{c}\text { POC } \\
\text { technology }\end{array}$ & $\begin{array}{c}\text { \# of } \\
\text { participants }\end{array}$ \\
\hline 1 & Barnabas & Lancet & 2014 & $\begin{array}{l}\text { South Africa, } \\
\text { Uganda }\end{array}$ & $\begin{array}{l}\text { prospective } \\
\text { observational }\end{array}$ & $\begin{array}{c}2011- \\
2013\end{array}$ & $\begin{array}{l}\text { home- } \\
\text { based }\end{array}$ & adults & Alere Pima & 3545 \\
\hline 2 & Bassett & PLoS One & 2014 & South Africa & $\begin{array}{l}\text { cost- } \\
\text { effectiveness }\end{array}$ & $\begin{array}{c}2010- \\
2011\end{array}$ & $\begin{array}{l}\text { mobile } \\
\text { clinic }\end{array}$ & adults & Alere Pima & NA \\
\hline 3 & Brown & IAS poster & 2013 & Tanzania & $\begin{array}{l}\text { retrospective } \\
\text { observational }\end{array}$ & $\begin{array}{c}2011- \\
2012\end{array}$ & clinics & adults & Alere Pima & $\mathrm{NI}$ \\
\hline 4 & Cassim & PLoS One & 2014 & South Africa & costing & $\begin{array}{c}2012- \\
2013\end{array}$ & NA & adults & Alere Pima & NA \\
\hline 5 & Chien & IAS poster & 2013 & Uganda & $\begin{array}{l}\text { retrospective } \\
\text { observational }\end{array}$ & $\begin{array}{c}2011- \\
2012\end{array}$ & clinics & adults & Alere Pima & $\mathrm{NI}$ \\
\hline 6 & Ciaranello & PLoS One & 2015 & South Africa & $\begin{array}{l}\text { cost- } \\
\text { effectiveness }\end{array}$ & NA & NA & $\begin{array}{l}\text { infants, } \\
\text { pregnant } \\
\text { women }\end{array}$ & generic & NA \\
\hline 7 & $\begin{array}{l}\text { De } \\
\text { Schacht }\end{array}$ & IAS abstract & 2012 & Mozambique & $\begin{array}{l}\text { retrospective } \\
\text { observational }\end{array}$ & $\begin{array}{c}2010- \\
2011\end{array}$ & $\begin{array}{l}\text { EGPAF } \\
\text { clinics }\end{array}$ & $\begin{array}{l}\text { pregnant } \\
\text { adults }\end{array}$ & Alere Pima & 3410 \\
\hline 8 & Desai & CROI poster & 2015 & Kenya & $\begin{array}{l}\text { prospective } \\
\text { RCT }\end{array}$ & $\begin{array}{c}2013- \\
2014\end{array}$ & $\begin{array}{l}\text { home- } \\
\text { based/ } \\
\text { clinics }\end{array}$ & adults & Alere Pima & 770 \\
\hline 9 & Dhoot & IJSA & 2013 & UK & $\begin{array}{l}\text { retrospective } \\
\text { observational }\end{array}$ & $\begin{array}{c}2011- \\
2012\end{array}$ & $\mathrm{NI}$ & adults & Alere Pima & 44 \\
\hline 10 & Faal & JAIDS & 2011 & South Africa & $\begin{array}{l}\text { prospective } \\
\text { RCT }\end{array}$ & 2009 & clinic & adults & $\begin{array}{l}\text { BD } \\
\text { FACSCount }\end{array}$ & 344 \\
\hline 11 & Fajardo & AIDS poster & 2014 & $9 \mathrm{sSA}$ & $\begin{array}{l}\text { retrospective } \\
\text { observational }\end{array}$ & $\begin{array}{c}2011- \\
2013\end{array}$ & $\begin{array}{l}\text { MSF } \\
\text { clinics }\end{array}$ & adults & Alere Pima & 25749 \\
\hline 12 & Grundy & presentation & unpublished & NA & $\begin{array}{l}\text { cost- } \\
\text { effectiveness }\end{array}$ & $\mathrm{NI}$ & $\mathrm{NI}$ & NA & generic & NA \\
\hline 13 & Hatzold & IAS abstract & 2011 & Zimbabwe & $\begin{array}{l}\text { retrospective } \\
\text { observational }\end{array}$ & $\mathrm{NI}$ & PSI clinics & adults & not indicated & 182 \\
\hline 14 & Herbert & $\begin{array}{l}\text { HIV } \\
\text { Medicine }\end{array}$ & 2011 & UK & $\begin{array}{l}\text { retrospective } \\
\text { observational }\end{array}$ & $\begin{array}{c}2010- \\
2011\end{array}$ & clinic & adults & Alere Pima & 200 \\
\hline 15 & Hyle & PLoS One & 2014 & Mozambique & $\begin{array}{l}\text { cost- } \\
\text { effectiveness }\end{array}$ & NA & NA & adults & Alere Pima & NA \\
\hline 16 & Jani & Lancet & 2011 & Mozambique & $\begin{array}{l}\text { retrospective } \\
\text { observational }\end{array}$ & $\begin{array}{c}2009- \\
2010\end{array}$ & clinics & adults & Alere Pima & 1021 \\
\hline 17 & Jani & AIDS & 2015 & Mozambique & $\begin{array}{l}\text { retrospective } \\
\text { observational }\end{array}$ & $\begin{array}{c}2013- \\
2014\end{array}$ & clinics & adults & Alere Pima & 103795 \\
\hline 18 & Larson & PLoS One & 2012 & South Africa & costing & NA & $\begin{array}{l}\text { mobile } \\
\text { clinic }\end{array}$ & adults & Alere Pima & NA \\
\hline 19 & Larson & JAIDS & 2012 & South Africa & $\begin{array}{l}\text { retrospective } \\
\text { observational }\end{array}$ & $\begin{array}{c}2010- \\
2011\end{array}$ & $\begin{array}{l}\text { mobile } \\
\text { clinic }\end{array}$ & adults & Alere Pima & 508 \\
\hline 20 & Larson & $\begin{array}{l}\text { AIDS Res } \\
\text { Tre }\end{array}$ & 2013 & South Africa & $\begin{array}{l}\text { retrospective } \\
\text { observational }\end{array}$ & $\begin{array}{c}2008- \\
2010\end{array}$ & clinic & adults & Alere Pima & 897 \\
\hline 21 & Larson & IAS abstract & 2011 & South Africa & $\begin{array}{l}\text { retrospective } \\
\text { observational }\end{array}$ & 2010 & clinic & adults & $\begin{array}{l}\text { BD } \\
\text { FACSCount }\end{array}$ & 538 \\
\hline 22 & Muchedzi & IAS abstract & 2012 & Zimbabwe & $\begin{array}{l}\text { retrospective } \\
\text { observational }\end{array}$ & 2011 & $\begin{array}{l}\text { EGPAF } \\
\text { clinics }\end{array}$ & $\begin{array}{l}\text { pregnant } \\
\text { adults }\end{array}$ & Alere Pima & 2310 \\
\hline 23 & Myer & JAIDS & 2015 & South Africa & $\begin{array}{l}\text { prospective } \\
\text { observational }\end{array}$ & $\begin{array}{c}2010- \\
2013\end{array}$ & clinic & $\begin{array}{l}\text { pregnant } \\
\text { adults }\end{array}$ & Alere Pima & 19432 \\
\hline 24 & Myer & AIDS Care & 2012 & South Africa & $\begin{array}{l}\text { retrospective } \\
\text { observational }\end{array}$ & 2011 & clinic & $\begin{array}{l}\text { pregnant } \\
\text { adults }\end{array}$ & Alere Pima & 2290 \\
\hline 25 & Obi & unclear & 2013 & UK & $\begin{array}{l}\text { prospective } \\
\text { observational }\end{array}$ & $\mathrm{NI}$ & hospital & adults & Alere Pima & 199 \\
\hline
\end{tabular}


Table 1. (Continued)

\begin{tabular}{|c|c|c|c|c|c|c|c|c|c|c|}
\hline$\#$ & Author & Journal & Year & $\begin{array}{l}\text { Countries of } \\
\text { study }\end{array}$ & Type of study & $\begin{array}{l}\text { Years } \\
\text { of } \\
\text { study }\end{array}$ & Site type & Population & $\begin{array}{c}\text { POC } \\
\text { technology }\end{array}$ & $\begin{array}{c}\text { \# of } \\
\text { participants }\end{array}$ \\
\hline 26 & Patten & JIAS & 2013 & South Africa & $\begin{array}{l}\text { retrospective } \\
\text { observational }\end{array}$ & $\begin{array}{c}2010- \\
2012\end{array}$ & clinics & youth, 12-25y & Alere Pima & 576 \\
\hline 27 & Rioja & IAS poster & 2013 & Cameroon & $\begin{array}{l}\text { retrospective } \\
\text { observational }\end{array}$ & 2012 & hospitals & adults & Alere Pima & $\mathrm{NI}$ \\
\hline 28 & Rosen & CROI poster & 2015 & South Africa & $\begin{array}{l}\text { prospective } \\
\text { RCT }\end{array}$ & $\begin{array}{c}2013- \\
2014\end{array}$ & clinics & adults & Alere Pima & 598 \\
\hline 29 & Tsibolane & $\begin{array}{l}\text { in } \\
\text { preparation }\end{array}$ & 2014 & South Africa & $\begin{array}{l}\text { retrospective } \\
\text { observational }\end{array}$ & 2014 & clinics & adults & Alere Pima & 1492 \\
\hline 30 & $\begin{array}{l}\text { van } \\
\text { Rooyen }\end{array}$ & JAIDS & 2013 & South Africa & $\begin{array}{l}\text { prospective } \\
\text { observational }\end{array}$ & $\begin{array}{c}2011- \\
2012\end{array}$ & $\begin{array}{l}\text { home- } \\
\text { based }\end{array}$ & adults & Alere Pima & 671 \\
\hline
\end{tabular}

$\mathrm{NI}$ : not indicated

NA: not applicable

doi:10.1371/journal.pone.0155256.t001

sample size per study was $830 \mathrm{HIV}$-positive patients. All studies included adults; however, one study focused on youth between 12 and 25 years of age. Five studies included pregnant women as the primary population. The included studies spanned eight countries, most within subSaharan Africa. All studies were conducted between 2009 and 2015. Two POC CD4 technologies were included with 25 of 27 studies using the Alere Pima POC CD4. There were three randomized control trials, four prospective observational studies, 17 retrospective observational studies, and six cost-effectiveness or costing studies.

Overall, there was a moderate risk of bias due to potential confounding temporal, facilityor individual-level factors. Most studies were observational cross-sectional studies. Participant samples in most studies were not consecutively recruited or studies failed to report the process of patient recruitment $(70 \%)$. The rationale for facility selection was not indicated or not randomized in most studies (72\%). Some studies used a pre-post analysis while others compared different groups of facilities with and without POC CD4 devices. There were some potential limitations in geographical applicability: most (90\%) studies were carried out in Africa in field settings and $50 \%$ were carried out in one country (South Africa). Additionally, most studies (78\%) did not include POC CD4 testing using finger-prick samples or failed to report the specimen type.

\section{Timeliness of testing and ART initiation}

POC CD4 technologies reduced test turnaround times from HIV diagnosis to CD4 test and HIV diagnosis to ART initiation when compared with conventional laboratory-based testing (Fig 2). The time from HIV diagnosis to CD4 test had a pooled mean of 10.5 days with conventional laboratory-based testing. This was reduced to a pooled mean of 0.1 days with POC CD4 testing. The time from HIV diagnosis to ART initiation was reduced from a mean of 31.5 days with conventional laboratory-based testing to a mean of 9.0 days with POC CD4 testing.

\section{Retention along the testing and treatment cascade}

POC CD4 improved retention between several steps along the testing and treatment cascade. Pooled proportions of patients reaching the following step in the cascade were significantly higher for POC CD4 compared to conventional laboratory-based testing (Fig 3). The proportion of patients who received a CD4 test after HIV testing increased from 70\% (95\% CI: 62- 


\section{a. Turnaround time between HIV diagnosis and CD4 test (days) (4 studies)}

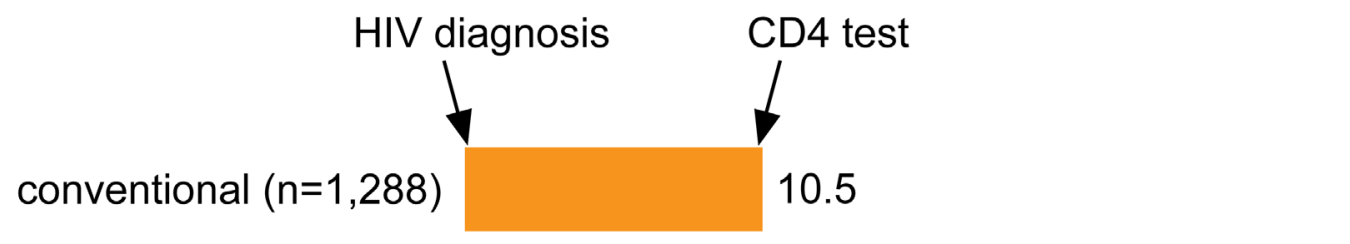

$\operatorname{POC}(n=1,719) \mid 0.1$

b. Turnaround time between HIV diagnosis and ART initiation (days) (2 studies)

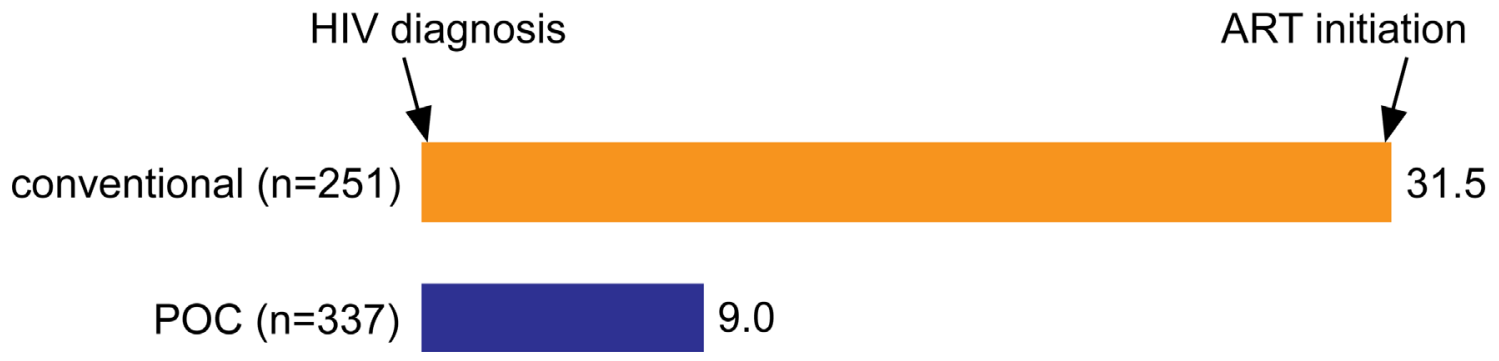

Fig 2. Mean turnaround times in days between two stages in the testing and treatment cascade. (a) CD4 test conducted to CD4 test result received, (b) HIV diagnosis and ART initiation. Orange bars represent the mean turnaround times for conventional laboratory-based testing, while blue bars represent the mean turnaround times for POC CD4 testing.

doi:10.1371/journal.pone.0155256.g002

$78 \%$ ) with conventional laboratory-based testing to 87\% (95\% CI: 83-91\%) with POC CD4 testing (RR: $1.21 ; 95 \%$ CI: $1.15-1.27 ; \mathrm{p}<0.001$ ). Significantly more patients received their CD4 test result after POC testing (95\%; 95\% CI: 94-97\%) compared to conventional laboratorybased testing (88\%; 95\% CI: 86-90\%) (RR: 1.07; 95\% CI: 1.04-1.19; $\mathrm{p}<0.001)$. Patients had a $58 \%$ higher likelihood of being retained prior to $\mathrm{CD} 4$ testing with POC compared to conventional laboratory-based testing, 83\% (95\% CI: 76-90\%) versus 53\% (95\% CI: 41-65); RR: 1.58; $1.35-1.85 ; \mathrm{p}<0.001)$. Additionally, significantly more patients were retained between CD4 testing and ART initiation with POC CD4 (72\%; 95\% CI: 59-85) compared with conventional laboratory-based testing (60\%; 95\% CI: 47-74) (RR: 1.16; 1.03-1.31; $\mathrm{p}=0.01)$.

\section{Literature review of cost-effectiveness of POC CD4}

Four studies looked at the cost-effectiveness of POC CD4 testing. A study from Mozambique found a 0.7-year increase in the projected life expectancy using POC CD4 compared to conventional laboratory-based testing [31]; POC CD4 was found to be cost-effective with an ICER/life year saved of $\$ 500$. In a mobile unit in South Africa, an increase of 0.71 years and an ICER/life year saved of $\$ 2,400$ USD was estimated to result from the inclusion of POC CD4 testing [19] as part of the overall mobile unit. Another study from South Africa focused on maternal to child transmission (MTCT) rates and observed a $0.4 \%$ reduction in transmission with the use of POC CD4 over conventional laboratory-based testing; however, this study was completed before Option B (ART for pregnant and breastfeeding women during the mother-to-child transmission risk period and maintain after cessation of breastfeeding for those eligible based on their own health) or Option B+ (lifelong ART for all pregnant and breastfeeding women 
Figure $3 a$

\author{
HIV testing to CD4 testing \\ CD4 testing to receipt of result
}

CD4 testing to ART initiation, of eligible

HIV testing to ART initiation

Retained pre-CD4 testing

Retained pre-ART initiation, of eligible

${ }^{*} \mathrm{p}=0.02$

${ }^{* *} p=0.01$

$* * * 0<0.001$

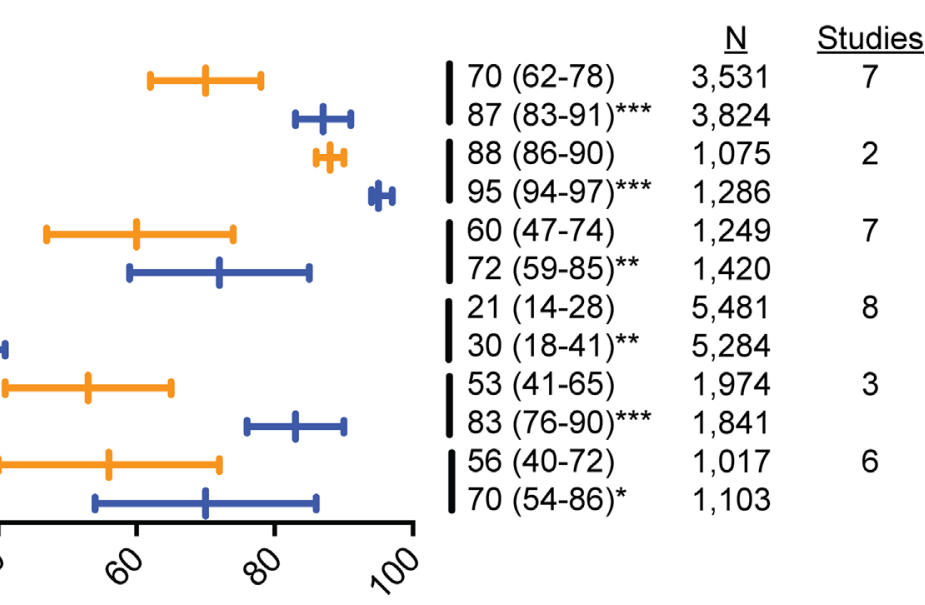

Figure $3 b$

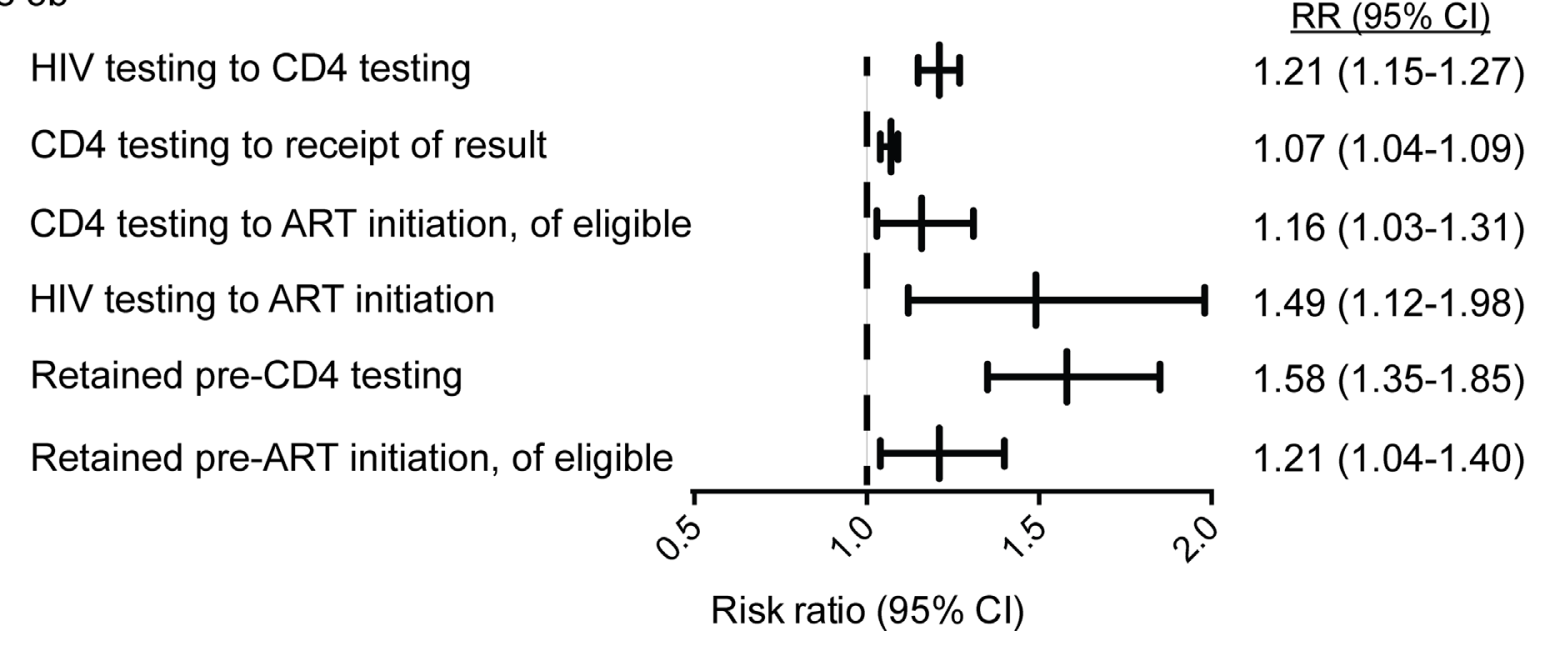

Fig 3. Proportions and risk ratios of patients reaching the next stage in the testing and treatment cascade. (a) Proportions of patients reaching the next stage in the testing and treatment cascade. Orange dashes and bars represent the estimated proportion of retention and $95 \%$ confidence intervals of patients receiving conventional laboratory-based testing, while blue dashes and bars represent the estimated proportion of retention and $95 \%$ confidence intervals of patients receiving POC CD4 testing. (b) Risk ratios for the likelihood of retention until the next stage in the testing and treatment cascade.

doi:10.1371/journal.pone.0155256.g003

living with HIV) were introduced [22,47]. Finally, a study from Malawi reported the cost per life saved with POC CD4 testing was $\$ 148.30$ compared to $\$ 165.50$ with conventional laboratory-based testing [28].

\title{
Literature review of acceptability
}

Two studies, both from the UK, assessed the acceptability of POC CD4 testing. The first study, reported that $>80 \%$ of patients found waiting 20 minutes for test results acceptable, while approximately $60 \%$ found the POC test preferable to conventional laboratory-based testing [30]. The second study found POC CD4 testing to be highly accepted compared to conventional laboratory-based testing; both new and stable patients reported significant time reductions of clinic visits [41]. 


\section{Discussion}

POC CD4 technologies have been implemented in over 2,000 health care facilities in at least 70 countries around the world with large, well-established programs in several countries in subSaharan Africa, Southeast Asia, and Central and South America [48]. This level of scale-up has provided a good opportunity to assess the clinical impact of POC CD4 testing. Many studies have reported positive impact on turnaround times, rates of ART initiation, and loss to follow up when POC CD4 is used compared to conventional laboratory testing in the current public health approach of utilizing CD4 as a gateway to ART.

A previous systematic review of 15 published studies reported an increased likelihood of having $\mathrm{CD} 4$ measured $(\mathrm{OR}=4.1)$, an increased likelihood of receiving a $\mathrm{CD} 4$ result $(\mathrm{OR}=2.8)$, an increased likelihood of proceeding from $\mathrm{CD} 4$ to $\mathrm{ART}$ initiation $(\mathrm{OR}=1.8)$, a reduced test turn-around time by 9 days and a reduced time from $\mathrm{CD} 4$ testing to receiving the result by 17 days [14]. Consistent with these previous findings, our review found that POC CD4 improved the timeliness of testing and retention of patients along the testing and treatment cascade. Time between HIV diagnosis and CD4 test and between HIV diagnosis and ART initiation were substantially reduced with the use of POC CD4 when compared to conventional laboratory-based CD4 testing. Retention along the testing and treatment cascade was significantly improved with POC CD4 testing, notably between HIV testing to CD4 testing, receipt of CD4 results, and CD4 testing and ART initiation. Finally, there was some evidence that POC CD4 was cost-effective and acceptable.

There are several limitations to this review. First, although both observational and randomized evidence was sought, most of the included studies were observational; such study designs may better reflect implementation practice, but are at higher risk of bias. All but five studies used the Alere Pima ${ }^{\text {ma }}$ POC CD4 platform as the intervention. While it is not anticipated that different POC CD4 technologies with similar test times and error rates would result in variable patient impact, this could not be assessed with the limited data available. Also, participants in most studies were not consecutively recruited or failed to report the process of patient recruitment, while the rationale for facility selection was not indicated or not randomized in most studies. The possibility exists that some studies may suffer from patient or facility selection bias. Another limitation is that the applicability of these findings beyond Africa is unclear as almost all studies were carried out in Africa, despite at least 70 countries and many resourcelimited countries having adopted POC CD4 technologies [48]. Finally, the findings were heterogeneous across studies (S3 Fig). Little detail was provided on the function of the conventional testing systems; however, the variable findings were likely due to significantly diverse quality of the conventional laboratories and related systems across different settings and countries included in the analysis.

The cost-effectiveness of POC CD4 is well-defined; however, affordability analyses with clear, detailed costing would allow stakeholders to carefully consider the adoption and scale-up of POC CD4 in light of changing guidelines and restricted budgets. Also, operational implementation guidance and tools based on best practice experiences would be valuable to inform use of these technologies. Furthermore, guidelines and optimal models for ensuring high quality, reliable test results for both rapid and point of care tests would be valuable.

Recent WHO Consolidated ART guidelines recommend treating all patients living with HIV, regardless of CD4 count, and using viral load testing to monitor patients on ART [5,47]. CD4 testing is, however, recommended for monitoring opportunistic infections of unstable or sick patients. The frequency and utility of CD4 testing may, therefore, decline in the future; however, many national programs in high HIV burden countries have only begun implementing routine viral load testing and few have adopted the treat all recommendation into national policies. 
Widespread uptake and decentralization of rapid diagnostic tests for major public health challenges, including HIV, tuberculosis and malaria, have led to significant gains in health provision and greater access to treatment, particularly in resource-limited settings [49]. While centralized laboratory networks are important for high throughput sample processing and quality control, they are unable to provide access to same day testing services to all patients in need. Also, sample transportation networks can be weak in many resource-limited settings resulting in long test turnaround times. POC tests are rapid, easy to use, and significantly improve retention of patients along the testing and treatment cascade and reduce the time from diagnosis to treatment compared to conventional laboratory-based testing. For POC tests to contribute maximally to laboratory networks, however, supportive systems such as supply chain, training and monitoring, quality assurance, service and maintenance, and data management must be built into the testing network and strengthened for improved patient care.

\title{
Supporting Information
}

\section{S1 Fig. Completed 2009 PRISMA Checklist. (DOC)}

\author{
S2 Fig. EMBASE Search Strategy. \\ (DOCX)
}

S3 Fig. Forest plots of each outcome analyzed. (TIF)

\section{Author Contributions}

Conceived and designed the experiments: LV JM NF TP. Performed the experiments: LV CB LH. Analyzed the data: LV JM CB NF TP. Wrote the paper: LV JM CB LH NF TP.

\section{References}

1. Hulgan T, Shepherd BE, Raffanti SP, Fusco JS, Beckerman R, Barkanic G et al. (2007) Absolute count and percentage of CD4+ lymphocytes are independent predictors of disease progression in HIVinfected persons initiating highly active antiretroviral therapy. J Infect Dis 195: 425-431. PMID: 17205482

2. Kagaayi J, Makumbi F, Nakigozi G, Wawer MJ, Gray RH, Serwadda D et al. (2007) WHO HIV clinical staging or CD4 cell counts for antiretroviral therapy eligibility assessment? An evaluation in rural Rakai district, Uganda. AIDS 21: 1208-1210. PMID: 17502733

3. O'Brien WA, Hartigan PM, Martin D, Esinhart J, Hill A, Benoit S et al. (1996) Changes in plasma HIV-1 RNA and CD4+ lymphocyte counts and the risk of progression to AIDS. Veterans Affairs Cooperative Study Group on AIDS. N Engl J Med 334: 426-431. PMID: 8552144

4. Post FA, Wood R, Maartens G (1996) CD4 and total lymphocyte counts as predictors of HIV disease progression. QJM 89: 505-508. PMID: 8759490

5. World Health Organization (2015) Guideline on when to start antiretroviral therapy and on pre-exposure prophylaxis for HIV.

6. Ford N, Meintjes G, Pozniak A, Bygrave H, Hill A, Peter T et al. (2015) The future role of CD4 cell count for monitoring antiretroviral therapy. The Lancet Infectious Diseases 15: 241-247. doi: 10.1016/ S1473-3099(14)70896-5 PMID: 25467647

7. Gilks CF, Walker AS, Munderi P, Kityo C, Reid A, Katabira E et al. (2013) A single CD4 test with 250 cells/mm3 threshold predicts viral suppression in HIV-infected adults failing first-line therapy by clinical criteria. PLoS ONE 8: e57580. doi: 10.1371/journal.pone.0057580 PMID: 23437399

8. Govindasamy D, Ford N, Kranzer K (2012) Risk factors, barriers and facilitators for linkage to antiretroviral therapy care: a systematic review. AIDS 26: 2059-2067. doi: 10.1097/QAD.0b013e3283578b9b PMID: 22781227 
9. Kranzer K, Govindasamy D, Ford N, Johnston V, Lawn SD (2012) Quantifying and addressing losses along the continuum of care for people living with HIV infection in sub-Saharan Africa: a systematic review. J Int AIDS Soc 15: 17383. doi: 10.7448/IAS.15.2.17383 PMID: 23199799

10. Mugglin C, Estill J, Wandeler G, Bender N, Egger M, Gsponer T et al. (2012) Loss to programme between HIV diagnosis and initiation of antiretroviral therapy in sub-Saharan Africa: systematic review and meta-analysis. Trop Med Int Health 17: 1509-1520. doi: 10.1111/j.1365-3156.2012.03089.x PMID: 22994151

11. Rosen S, Fox M (2011) Retention in HIV care between testing and treatment in sub-Saharan Africa: a systematic review. PLoS Med 8: e1001056. doi: 10.1371/journal.pmed.1001056 PMID: 21811403

12. UNITAID (2013) HIV/AIDS Diagnostic Technology Landscape, 3rd edition.

13. Jani IV, Sitoe NE, Alfai ER, Chongo PL, Quevedo JI, Rocha BM et al. (2011) Effect of point-of-care CD4 cell count tests on retention of patients and rates of antiretroviral therapy initiation in primary health clinics: an observational cohort study. Lancet 378: 1572-1579. doi: 10.1016/S0140-6736(11)61052-0 PMID: 21951656

14. Wynberg E, Cooke G, Shroufi A, Reid SD, Ford N (2014) Impact of point-of-care CD4 testing on linkage to HIV care: a systematic review. J Int AIDS Soc 17: 18809. doi: 10.7448/IAS.17.1.18809 PMID: 24447595

15. Moher D, Liberati A, Tetzlaff J, Altman D (2009) Preferred Reporting Items for Systematic Reviews and Meta-Analyses: The PRISMA Statement. PLoS Med 6: e1000097. doi: 10.1371/journal.pmed. 1000097 PMID: 19621072

16. Whiting PF, Rutjes AW, Westwood ME, Mallett S, Deeks JJ, Reitsma JB et al. (2011) QUADAS-2: a revised tool for the quality assessment of diagnostic accuracy studies. Ann Intern Med 155: 529-536. doi: 10.7326/0003-4819-155-8-201110180-00009 PMID: 22007046

17. Takkouche B, Cadarso-Suárez C, Spiegelman D (1999) Evaluation of old and new tests of heterogeneity in epidemiologic meta-analysis. American Journal of Epidemiology 150: 206-215. PMID: 10412966

18. Barnabas R, Van Rooyen $H$, Tumwesigye $E$, Murnane $P$, Baeten J, Humphries $\mathrm{H}$ et al. (2014) Initiation of antiretroviral therapy and viral suppression after home HIV testing and counselling in KwaZulu-Natal, South Africa, and Mbarara district, Uganda: a prospective, observational intervention study. The Lancet HIV 1: e68-e76. PMID: 25601912

19. Bassett I, Govindasamy D, Erlwanger A, Hyle EP, Kranzer K, Van Schaik N et al. (2014) Mobile HIV Screening in Cape Town, South Africa: Clinical Impact, Cost and Cost-Effectiveness. PLoS ONE 9: e85197. doi: 10.1371/journal.pone.0085197 PMID: 24465503

20. Brouillette AM, Chien E, Nyegenye W, Tenywa T, Grosz J (2013) Using finger-prick blood collection samples for the Pima POC CD4 device increases access to CD4 testing. 7th IAS Conference on HIV Pathogenesis and Treatment; Kuala Lumpur Abstract WEPE607.

21. Cassim N, Coetzee LM, Schnippel K, Glencross DK (2014) Estimating implementation and operational costs of an integrated tiered CD4 service including laboratory and point of care testing in a remote health district in South Africa. PLoS ONE 9: e115420. doi: 10.1371/journal.pone.0115420 PMID: 25517412

22. Ciaranello AL, Myer L, Kelly K, Christensen S, Daskilewicz K, Doherty K et al. (2015) Point-of-Care CD4 Testing to Inform Selection of Antiretroviral Medications in South African Antenatal Clinics: A Cost-Effectiveness Analysis. PLoS ONE 10: e0117751. doi: 10.1371/journal.pone.0117751 PMID: 25756498

23. De Schacht C, Lucas C, Sitoe NE, Manuel I, Tobaiwa O, Ramanial N et al. (2012) Point-of-care CD4 testing leads to increased uptake of antiretroviral therapy among pregnant women in Gaza province, Mozambique. 19th International AIDS Conference: Abstract no. THPE079.

24. Desai MA, Okal D, Rose C, Ndivo R, Williams T, Otieno F et al. (2015) Point-of-Care CD4 (Pima) Impact on Linkage to Care with Home-Based HIV Testing, Kenya. Conference on Retroviruses and Opportunistic Infections: Abstract \#632LB.

25. Dhoot S, Stack R, Madden P, McMillan S, Jones R, Day S (2013) CD4 point-of-care testing to guide management in patients newly diagnosed with HIV. International Journal of STD \& AIDS 4.

26. Faal $M$, Naidoo N, Glencross DK, Venter WD, Osih R (2011) Providing immediate CD4 count results at HIV testing improves ART initiation. J Acquir Immune Defic Syndr 58: e54-e59. doi: 10.1097/QAI. Ob013e3182303921 PMID: 21857356

27. Fajardo N, Metcalf C, Piriou E, Gueguen M, Maman D, Chaillet P et al. (2014) High frequency of invalid CD4 test results using the Alere Pima CD4 analyzer in field projects in nine countries. 20th Internationa AIDS Conference: Abstract WEPE040. 
28. Grundy CL, Medina Lara A, Winogron D, Croucher AP, Batz H-G, Hallett TB et al. (2014) Point-of-care CD4 tests can increase life-years saved with reduced costs compared to flow cytometric CD4. 6th IAS Conference on HIV Pathogenesis and Treatment: Abstract No MOAD0105.

29. Hatzold K, Gudekeya S, Museta M, Maparutza S, Mangwiro A, Bhattacharya G et al. (2011) Improved access to HAART through Point of Care CD4 cell count testing integration into HIV testing and counseling services in Zimbabwe. 6th IAS Conference on HIV Pathogenesis, Treatment and Prevention: Abstract No CDD080.

30. Herbert S, Carrick G, Edwards S, Copas A, George B, Long L et al. (2011) Enhancing services for HIVpositive patients: the role of point-of-care CD4 testing. HIV Medicine: Abstract No. P4 12: 15.

31. Hyle EP, Jani IV, Lehe J, Su AE, Wood R, Quevedo J et al. (2014) The Clinical and Economic Impact of Point-of-Care CD4 Testing in Mozambique and Other Resource-Limited Settings: A Cost-Effectiveness Analysis. PLoS Med 11: e1001725. doi: 10.1371/journal.pmed.1001725 PMID: 25225800

32. Jani IV, Quevedo JI, Tobaiwa O, Bollinger T, Sitoe NE, Chongo P et al. (2016) Use of mobile phone technology to improve the quality of point-of-care testing in a low resource setting. AIDS accepted.

33. Larson B, Ndibongo B, Bistline K, Xulu T, Brennan A, Long L et al. (2011) Point-of-care CD4 testing after HIV diagnosis to reduce losses to initiation of antiretroviral therapy: an evaluation of a pilot program at the Themba Lethu Clinic, Johannesburg, South Africa. 6th IAS Conference on HIV Pathogenesis, Treatment and Prevention: Abstract No MOPE450.

34. Larson B, Schnippel K, Ndibongo B, Long L, Fox M, Rosen S (2012) How to Estimate the Cost of Pointof-Care CD4 Testing in Program Settings: An Example Using the Alere Pima ${ }^{\mathrm{TM}}$ Analyzer in South Africa. PLoS ONE 7: e35444. doi: 10.1371/journal.pone.0035444 PMID: 22532854

35. Larson B, Schnippel K, Ndibongo B, Xulu T, Brennan A, Long L et al. (2012) Rapid Point-of-Care CD4 Testing at Mobile HIV Testing Sites to Increase Linkage to Care. JAIDS Journal of Acquired Immune Deficiency Syndromes 61: e13-e17. PMID: 22659650

36. Larson B, Schnippel K, Brennan A, Long L, Xulu T, Maotoe T et al. (2013) Same-Day CD4 Testing to Improve Uptake of HIV Care and Treatment in South Africa: Point-of-Care Is Not Enough. AIDS Research and Treatment 2013: 1-7.

37. Muchedzi A, Chadambuka A, Chikwinya B, Mahomva A (2012) Evaluating the effect of the use of pointof-care CD4 machines on access to antiretroviral therapy (ART) eligibility screening and ART initiation for HIV-positive pregnant women in Zimbabwe: towards elimination of new paediatric HIV infection by 2015. 19th International AIDS Conference, Abstract no. TUPDE0204.

38. Mwanja A, Brown L, Mtumbuka E, Shayo C, Vojnov L (2013) The introduction of a POC CD4 technology increases patient access to and the impact of CD4 testing. 7th IAS Conference on HIV Pathogenesis and Treatment: Abstract WEPE608.

39. Myer L, Zulliger R, Black S, Pienaar D, Bekker LG (2012) Pilot programme for the rapid initiation of antiretroviral therapy in pregnancy in Cape Town, South Africa. AIDS Care 24: 986-992. doi: 10.1080/ 09540121.2012.668173 PMID: 22519561

40. Myer L, Phillips T, Manuelli V, Mcintyre J, Bekker LG, Abrams E (2015) Implementation and Operational Research. JAIDS Journal of Acquired Immune Deficiency Syndromes 69: e57-e65.

41. Obi A, Jones C, Pizzo E, Vera J, Hart C, Mackie N et al. (2013) CD4 point-of-care testing improves patient satisfaction and reduces recalls to clinic. HIV Medicine: Abstract No. O3 14.

42. Patten GE, Wilkinson $L$, Conradie $K$, Isaakidis $P$, Harries A, Edginton ME et al. (2013) Impact on ART initiation of point-of-care CD4 testing at HIV diagnosis among HIV-positive youth in Khayelitsha, South Africa. J Int AIDS Soc 16: 18518. doi: 10.7448/IAS.16.1.18518 PMID: 23830642

43. Rioja MR, Nzuobontane D, Munyaburanga F, Khan EM, Muffih PT, Shang J et al. (2013) CD4 count testing capacity in rural health districts in Cameroon through point-of-care technology. 7th IAS Conference on HIV Pathogenesis and Treatment: Abstract No WEPE609.

44. Rosen S, Maskew M, Fox MP, Nyoni C, Mongwengyana C, Malete G et al. (2015) Rapid ART Initiation Reduces Loss Between HIV Testing and Treatment: The RapIT Trial. Conference on Retroviruses and Opportunistic Infections: Abstract \#1091.

45. Tsibolane Y, Van Turha L, Maharaj K, Rose A, Boeke C, Peter T et al. Point-of-Care CD4 technology implementation in Free State, South Africa associated with better patient health outcomes. manuscript in preparation.

46. Van Rooyen H, Barnabas R, Baeten J, Phakathi Z, Joseph P, Krows M et al. (2013) High HIV Testing Uptake and Linkage to Care in a Novel Program of Home-Based HIV Counseling and Testing With Facilitated Referral in KwaZulu-Natal, South Africa. JAIDS Journal of Acquired Immune Deficiency Syndromes 64: e1-e8. doi: 10.1097/QAI.0b013e31829b567d PMID: 23714740

47. World Health Organization (2013) Consolidated Guidelines on the Use of Antiretroviral Drugs for Treating and Preventing HIV Infection: Recommendations for a Public Health Approach. 
48. AlereHIV.com Studies and Implementation Map. Available: http://www.alerehiv.com/ww/home/studiesand-implementation.html via the Internet.

49. Jani IV, Peter TF (2013) How point-of-care testing could drive innovation in global health. N Engl J Med 368: 2319-2324. doi: 10.1056/NEJMsb1214197 PMID: 23758238 